\title{
Multiple-allergen oral immunotherapy improves quality of life in caregivers of food-allergic pediatric subjects
}

Iris M Otani ${ }^{1}$, Philippe Bégin ${ }^{1}$, Clare Kearney ${ }^{1}$, Tina LR Dominguez ${ }^{1}$, Anjuli Mehrotra ${ }^{1}$, Liane R Bacal' Shruti Wilson ${ }^{1}$ and Kari Nadeau ${ }^{1,2^{*}}$

\begin{abstract}
Background: Food allergy (FA) negatively affects quality of life in caregivers of food-allergic children, imposing a psychosocial and economic burden. Oral immunotherapy (OIT) is a promising investigational therapy for FA. However, OIT can be a source of anxiety as it carries risk for allergic reactions. The effect of OIT with multiple food allergens ( $\mathrm{mOIT}$ ) on FA-specific health-related quality of life (HRQL) has never been studied in participants with multiple, severe food allergies. This study is the first to investigate the effects of mOIT on FA-related HRQL in caregivers of pediatric subjects.
\end{abstract}

Methods: Caregiver HRQL was assessed using a validated Food Allergy Quality of Life - Parental Burden (FAQL-PB) Questionnaire (J Allergy Clin Immunol 114(5):1159-1163, 2004). Parents of participants in two single-center Phase I clinical trials receiving $\mathrm{mOIT}(\mathrm{n}=29)$ or rush $\mathrm{mOIT}$ with anti-lgE (omalizumab) pre-treatment $(\mathrm{n}=11)$ completed the FAQL-PB prior to study intervention and at 2 follow-up time-points ( 6 months and 18 months). Parents of subjects not receiving OIT (control group, $n=10$ ) completed the FAQL-PB for the same time-points.

Results: HRQL improved with clinical (change $<-0.5)$ and statistical $(p<0.05)$ significance in the mOIT group (baseline mean 3.9, 95\% Cl 3.4-4.4; 6-month follow-up mean 2.5, 95\% Cl 2.0-3.0; 18-month follow-up mean 1.8, 95\% Cl 1.4-2.1) and rush mOIT group (baseline mean 3.9, 95\% Cl 3.1-4.7; 6-month follow-up mean 1.7, 95\% Cl 0.9-2.6; 18-month follow-up mean 1.3, 95\% Cl 0.3-2.4). HRQL scores did not significantly change in the control group $(n=10)$.

Conclusion: Multi-allergen OIT with or without omalizumab leads to improvement in caregiver HRQL, suggesting that mOIT can help relieve the psychosocial and economic burden FA imposes on caregivers of food-allergic children.

Keywords: Oral immunotherapy, Omalizumab, Anti-lgE, Food allergy, Oral desensitization, Quality of life, Health-related quality of life

\section{Introduction}

Food allergy (FA) is an adverse immunologic response to dietary antigen with a reported prevalence of $8 \%$ in the United States. Approximately $30.4 \%$ of food-allergic participants are multi-sensitized, or allergic to more than one food allergen [1]. In Canada, the prevalence of pediatric food allergy has been reported to be $7.14 \%$ [2]. Currently,

\footnotetext{
* Correspondence: knadeau@stanford.edu

${ }^{1}$ Stanford Alliance for Food Allergy Research, Palo Alto, CA, USA

${ }^{2}$ Department of Pediatrics, Division of Immunology and Allergy, Stanford University, 269 Campus Drive, CCSR Building Suite 3215, Stanford, California 94305, USA
}

\section{Biomed Central}

(c) 2014 Otani et al.; licensee BioMed Central Ltd. This is an Open Access article distributed under the terms of the Creative Commons Attribution License (http://creativecommons.org/licenses/by/4.0), which permits unrestricted use, distribution, and reproduction in any medium, provided the original work is properly credited. The Creative Commons Public Domain Dedication waiver (http://creativecommons.org/publicdomain/zero/1.0/) applies to the data made available in this article unless otherwise stated. the only FDA-approved treatment for FA is food allergen avoidance and injectable epinephrine [3].

Food allergies have a significant negative impact on participants' quality of life [4-6]. The burden of FA on caregivers (buying special foods, limiting social encounters, foregoing full-time employment) has been reported to play a predominant role in the total annual economic burden of FA, \$24.8 billion [7]. Compared to those with single food allergies, those with multiple food allergies experience a greater decrease in quality of life $[5,8]$, are more likely to suffer from dietary deficiencies [9] and are less likely to outgrow their food allergies [10]. 
Oral immunotherapy (OIT) is a promising investigational therapy for food allergy [11]. We recently conducted two Phase I clinical trials showing the safety and feasibility of 1) an OIT protocol for desensitization to multiple allergens simultaneously (mOIT) [12] and 2) a protocol combining anti-IgE therapy (omalizumab) and a rush mOIT schedule to allow a rapid desensitization (rush mOIT) [13].

Although it is intuitive to think that successful desensitization to multiple food allergens would improve quality of life, safety analyses have shown that allergic reactions are common with OIT dosing. Although the majority of reactions are reported as mild, events requiring injectable epinephrine do occur [12,13]. This raises the question as to whether reactions with dosing outweigh the benefit gained from therapy, which can only be addressed by an objective evaluation of quality of life influenced specifically by health and disease, or health-related quality of life (HRQL) [14-16]. While single-allergen OIT has been found to result in HRQL improvement in participants with peanut or cow milk allergy $[17,18]$, this study is the first to investigate the effects of mOIT and of rush mOIT with omalizumab on FA-related HRQL.

\section{Methods}

\section{Participants}

Questionnaires were distributed to caregivers of 3 groups of participants: 2 experimental groups enrolled in 2 separate ongoing single-center Phase I clinical trials conducted under INDs with Stanford IRB approvals and 1 control group whose only intervention was food allergen avoidance. Written consent was obtained prior to study entry.

Eligibility criteria are described in detail in previous publications [12,13]. Briefly, in all the groups, participants older than 4 years were eligible for inclusion if they had proven sensitivity to their main food allergen documented by both a positive skin prick test specific IgE as well as positive allergic reaction in a double-blind placebo-controlled oral food challenge (DBPCFC) up to a cumulative dose of $182 \mathrm{mg}$ as per Bock's criteria [12,13]. To be included in the treatment, additional food allergens also needed to induce a reaction within a cumulative dose of $182 \mathrm{mg}$ on DBPCFC.

\section{Study intervention}

The intervention and medication used in the mOIT and rush mOIT groups have been described in detail previously $[12,13]$. Briefly, subjects meeting inclusion criteria were started on a daily dose of up to 5 multiple food allergens combined in an equivalent stoichiometric ratio (1:1:1:1:1) based on food protein content. In the mOIT group, participants underwent an initial dose escalation starting at $0.1 \mathrm{mg}$ of total food protein up to a maximum of $6 \mathrm{mg}$ if tolerated. The maximal tolerated dose determined daily home dose that was increased by $25 \%$ increments every other week at our research clinic based on dose tolerability. Participants took a median of 85 weeks to reach their maintenance dose of $4000 \mathrm{mg}$ protein per food. In the rush mOIT group, participants underwent a 16-week omalizumab treatment, starting 8 weeks prior to rush mOIT. They underwent rush desensitization up to $1250 \mathrm{mg}$ of total food protein on their first day, followed by similar biweekly increases in home doses. Final maintenance dose was reached at a median of 18 weeks.

\section{Questionnaire}

Health-related quality of life (HRQL) was assessed using a validated Food Allergy Quality of Life - Parental Burden (FAQL-PB) Questionnaire [1]. The FAQL-PB is a FA-specific HRQL questionnaire that measures parental burden associated with having a child with FA. It was originally validated in the United States by Cohen et al. and consists of 17 questions that are answered on a 7-point scale.

All patients in the mOIT and the rush mOIT trials who started the protocol between January 1 and April 1 2012 were asked to complete the questionnaire prior to study intervention. The same parent who filled out the questionnaire at baseline completed the subsequent follow-up questionnaires at a 6-month follow-up timepoint on OIT and an 18-month follow-up time-point. Only caregivers of participants aged less than 17-years were included to be consistent with the age group used in the validation phase of the FAQL-PB questionnaire by Cohen et al. [1].

During the same period, all consecutive subjects screened and meeting the same inclusion criteria as the mOIT and rush mOIT trials were asked to fill out the questionnaire. Those who were not included in the mOIT and rush mOIT trials despite meeting inclusion criteria due to lack of available space were asked to fill out follow-up questionnaires as an untreated control group.

\section{Statistics}

Comparisons between HRQL scores were made with the Wilcoxon for paired variables and the Mann-Whitney test for unpaired variables, as appropriate. A 2-tailed p-value of less than 0.05 was considered statistically significant.

Clinical relevance was assessed using the MID, or minimal clinically important difference. The MID has previously been defined as the smallest change in HRQL that participants perceive as clinically important. It has been estimated to be approximately 0.5 for scores graded on a 7-point scale in several HRQL questionnaires, including questionnaires assessing parental quality of life [19-23].

The therapeutic value of oral immunotherapy was determined by calculating the number-needed-to-treat (NNT) 
as done previously by van der Velde et al. [24,25]. The proportion of participants who benefited from multiallergen oral immunotherapy was calculated as the difference of the proportion of participants with clinically important improvement in HRQL in the mOIT group minus the proportion of participants with improvement in HRQL in the control group. The NNT is the reciprocal of the proportion of participants benefiting from OIT. All statistical analyses and graphing were carried out with GraphPad Prism software (GraphPad Software, San Diego, CA).

\section{Results}

During the initial recruitment period for the HRQL study, 29 participants started the MOIT trial and 11 participants started the rush mOIT trial. Caregivers of all these participants completed the FAQL-PB questionnaire at all required time-points. During the same period, 24 participants were screened and met criteria for entry into an OIT trial at our center. All caregivers accepted to complete the questionnaire as controls. Fourteen were eventually included in a trial prior to 6-month follow-up and were thus excluded from analysis. Of the 10 remaining participants, 2 were lost to follow-up prior to the 18-month follow-up. Baseline characteristics were similar between all 3 groups (Table 1).

At baseline, all three groups had a high and comparable HRQL score (mean 3.6 to 3.9) out of a maximum of 6 , indicating that all groups had a poor quality of life at baseline. Caregivers of participants in the mOIT group $(\mathrm{n}=29)$ had a significant improvement in HRQL score at 6-month follow-up (mean 2.5, 95\% CI 2.0-30) and 18-month follow-up (mean 1.8, 95\% CI 1.4-2.1) compared to baseline $(\mathrm{p}<0.0001)$. Caregivers of participants in the rush mOIT group $(n=11)$ also had a significant improvement in HRQL score at 6-month follow-up (mean 1.7, 95\% CI 0.9-2.6) and 18-month follow-up (mean 1.3, 95\% CI $0.3-2.4$ ) compared to baseline ( $\mathrm{p}=0.001$ and $\mathrm{p}=0.005$, respectively). HRQL worsened significantly $(\mathrm{p}<0.01)$ in the control group $(\mathrm{n}=10)$ from baseline (mean 3.6, 95\% CI 2.9-4.3) to 6-month follow-up (mean 4.3, 95\% CI 3.9-4.8). However, HRQL at 18-month follow-up (mean 4.3, 95\% CI 3.7-4.7) was comparable to baseline HRQL in the control group (Figure 1). We did not find any association between the number of foods or adverse events and the change in HRQL score in either group although we may have lacked power for such sub-group analysis.

With both interventions, the improvement was clinically relevant (decrease greater than -0.5 ) at both time points $(-1.9$ and -2.5 at 6 and 18 months with mOIT, -2.6 and -3.1 at 6 and 18 months with rush mOIT). The percentages of participants with clinically relevant changes in FAQL-PB HRQL scores are shown for all 3 groups in Figure 2A (6-month follow-up) and Figure 2B (18-month follow-up).
Table 1 Baseline demographics and clinical characteristics of pediatric subjects in the $\mathrm{mOIT}$, rush $\mathrm{mOIT}$, and control groups

\begin{tabular}{lccc}
\hline & mOIT* & Rush mOIT* & Control \\
\hline $\begin{array}{l}\text { Number of subjects } \\
\begin{array}{l}\text { Median age in years } \\
\text { (range) }\end{array}\end{array}$ & $8(4-13)$ & $7(4-16)$ & $8(4-14)$ \\
$\begin{array}{l}\text { Male } \\
\text { Coexisting atopic disease }\end{array}$ & $18(62 \%)$ & $8(72 \%)$ & $5(50 \%)$ \\
$\quad$ Atopic dermatitis & $20(69 \%)$ & $5(45 \%)$ & $5(50 \%)$ \\
$\quad$ Allergic rhinitis & $15(52 \%)$ & $6(55 \%)$ & $6(60 \%)$ \\
$\quad$ Asthma & $21(72 \%)$ & $8(73 \%)$ & $7(70 \%)$
\end{tabular}

Food allergies meeting criteria for inclusion on DBPCFC**

$\begin{array}{lccl}\text { Peanut } & 20(69 \%) & 7(64 \%) & 7(70 \%) \\ \text { Walnut } & 11(38 \%) & 5(45 \%) & 4(40 \%) \\ \text { Cashew } & 9(31 \%) & 6(55 \%) & 3(30 \%) \\ \text { Pecan } & 8(28 \%) & 5(45 \%) & 3(30 \%) \\ \text { Milk } & 8(28 \%) & 3(27 \%) & 2(20 \%) \\ \text { Egg } & 4(14 \%) & 4(36 \%) & 3(30 \%) \\ \text { Sesame } & 4(14 \%) & 0(0 \%) & 2(20 \%) \\ \text { Almond } & 3(10 \%) & 3(27 \%) & 2(20 \%) \\ \text { Hazelnut } & 2(7 \%) & 1(9 \%) & 2(20 \%)\end{array}$

Average number of desensitized foods

$3 \quad 4 \quad n / a$

Highest baseline food allergy test (median and range)

$\begin{array}{lccc}\text { SPT in mm } & 13.5(7-25.5) & 10.5(7-29.5) & 10.5(7-30.5) \\ \text { Specific lgE in ku/L } & 82.5(2.95->100) & 36.4(2->100) & 61(3.25->100) \\ \text { Lowest amount } & 32.7(0.1-182.7) & 32.7(0.1-182.7) & 32.7(0.1-182.7)\end{array}$
triggering reaction in DBPCFC in mg protein

*OIT = oral immunotherapy. **DBPCFC = double blind placebo controlled food challenge.

To assess therapeutic value, we calculated the NNT to induce a clinically relevant improvement in QOL. At the 6-month follow-up time-point, NNT for mOIT was 1.5 and 1.1 for rush multi-allergen OIT. At the 18-month follow-up time-point, NNT was 1.2 for both multi-allergen OIT and rush multi-allergen OIT.

We looked at individual question scores to see if changes seen in overall HRQL scores were distributed across all questions or due to changes in specific question scores (Figure 3). In the mOIT group, caregivers' answers showed a statistically significant $(\mathrm{p}<0.05)$ and clinically relevant (change $<-0.5$ ) change for all 17 questions (Additional file 1: Table S1) at the 6-month follow-up that persisted at the 18-month follow-up. Similarly, in the rush mOIT group, caregivers' answers showed a statistically significant and clinically relevant change for all but 2 questions at the 6-month and all but 1 question at the 18-month follow-up time-point. 


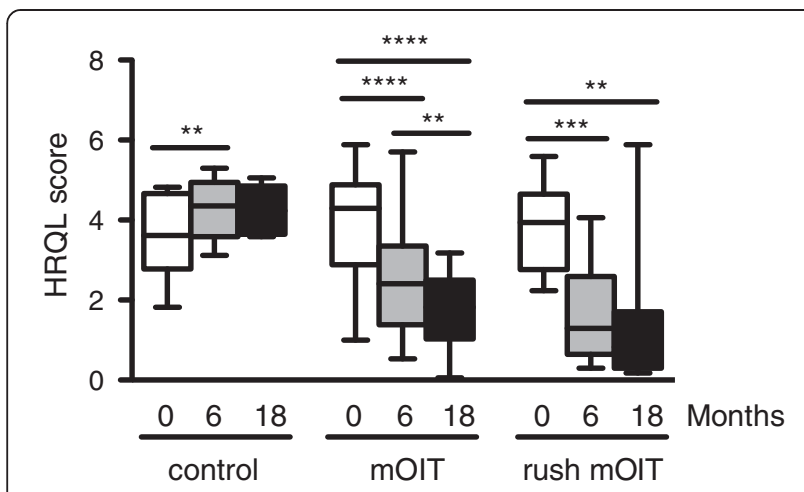

Figure $1 \mathrm{HRQL}$ scores improve in caregivers of participants on mOIT and rush mOIT. Median HRQL score at baseline, 6-month follow-up, and 18-month follow-up are shown for the control group, mOIT group, and rush mOIT group. Whiskers represent minimum and maximum values. Median HRQL scores were 3.6, 4.4, 4.2 at baseline, 6 months, and 18 months, respectively, for the control group; 4.3, 2.4, 1.8 for the mOlT group; 3.9, 1.3, 0.8 for the rush mOIT group. ${ }^{* *} p<0.01,{ }^{* * *} p=0.001,{ }^{* * *} p<0.0001$.

\section{Discussion}

Using a quality of life questionnaire specifically validated for food allergy, we have shown that two protocols for mOIT were associated with clinically and statistically significant increases in caregiver quality of life. This change persisted with 18 months of ongoing therapy and included all areas covered by the questionnaire. The effect was most pronounced after 18 months of rush mOIT combined with Omalizumab which showed a HRQL score decrease of 3.1 from median 3.9 to 0.8 (score ranked on a maximum of 6 ).

These findings are of major importance given the current question surrounding the role for OIT in the care for children with multiple food allergies. The efficacy of OIT is typically measured by the ability to tolerate food allergen after discontinuation of therapy (clinical tolerance or sustained unresponsiveness). Recent studies have shown limited rates of sustained unresponsiveness with OIT, raising concern about its relevance as an intervention for food allergy [26]. This study shows that desensitization itself, even without discontinuing therapy, provides significant and persistent improvement in caregiver quality of life. This suggests OIT can be of benefit to caregiver quality of life even in the absence of sustained unresponsiveness.

These results also suggest that the reaction profiles of mOIT and rush mOIT are acceptable and justified from a caregiver point-of-view and are much preferred to allergen avoidance. Home dosing reactions, which are expected and for which the patient is prepared may be less anxiety-producing than the constant fear of accidental reactions and uncertainty of day to day living with food allergy. In a review of 352 subjects desensitized to peanut, Wasserman and colleagues showed that severe reactions requiring epinephrine in the context of OIT were recognized and treated promptly and did not require additional intervention [27].
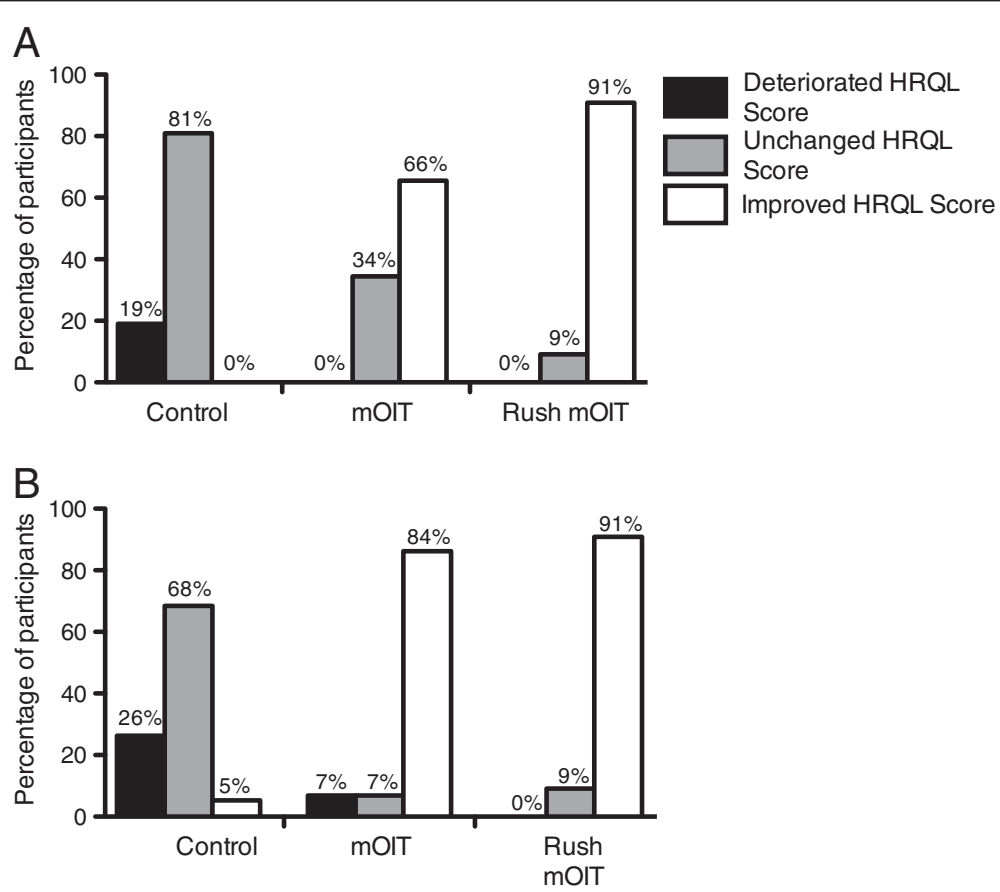

Figure 2 Percentages of participants with deterioration, no change, or improvement in HRQL scores. Percentages of participants whose HRQL scores deteriorated (change $>0.5$ ), remained unchanged (change between -0.5 and 0.5 ), or improved (change $<-0.5$ ) in the control group, mOIT group, and rush mOIT group at (A) 6-month follow-up and (B) 18-month follow-up. 

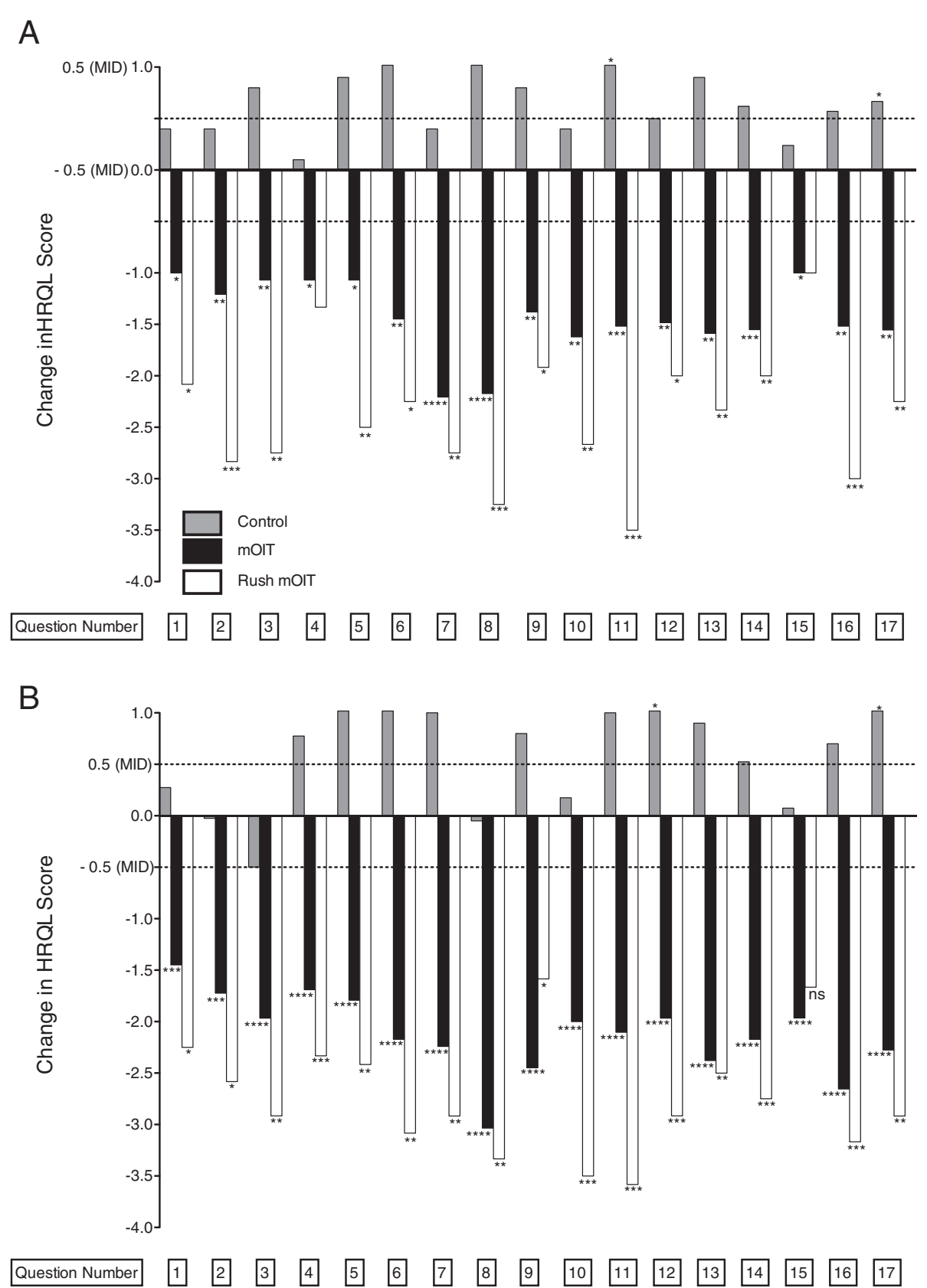

Figure 3 Changes in individual FAQL-PB question scores. Changes in individual FAQL-PB question scores are shown between and (A) 6-month follow-up and (B) 18-month follow-up. ${ }^{*} p<0.05,{ }^{* *} p<0.01,{ }^{* * *} p<0.001$, ${ }^{* * *} p<0.0001$. Bars without asterisks represent non-significant changes.

In addition to reducing reaction anxiety, the FAQL$\mathrm{PB}$ questionnaire showed that mOIT had an impact on various aspects of day to day living associated with an economic burden for families with food allergy. These include arranging special diets ( $\$ 1.7$ billion spent annually in the United States) and avoidance of unintentional exposure to food allergens including childcare arrangements ( $\$ 857$ million), changing schools ( $\$ 650$ million), and attending special summer camps ( $\$ 125$ million) [8].
This study is the first to examine the effects of multiallergen OIT protocols in caregivers of multi-sensitized participants. Two prior studies showed improvement in FA-specific HRQL with single-allergen OIT. These studies used a different questionnaire so their results cannot be directly compared to those presented here. To the best of our knowledge, the effect of single-allergen oral immunotherapy on HRQL has never been studied in participants with multiple, severe food allergies but one could assume that the effect would not be as drastic 
given it would only allow them to be less vigilant about one of their food allergens.

When comparing the two interventions, the magnitude of improvement was greater for the rush mOIT group, especially at the 6-month time point. Also, at 6month follow-up, a larger percentage of participants had improved HRQL scores in the rush mOIT group (91\%) when compared to the mOIT (66\%) group, whereas at 18-month follow-up, the percentage of participants with improved HRQL scores was similar between the rush mOIT (91\%) and mOIT (84\%) group. The greater and more rapid HRQL improvement with rush mOIT probably reflects the fact that subjects reach maintenance much faster in this group (median 18 weeks) compared to mOIT without omalizumab (median 85 weeks) $[12,13]$. It is unlikely to be related to a protective effect of omalizumab as reaction rates were similar in both groups.

One limitation to consider is that all subjects were recruited from volunteers. Although this potentially introduced selection bias toward more severely affected families, this bias reflects the patient population that would seek out additional therapy such as oral immunotherapy. Also, these were Phase I studies. Although the control group was not placebo-controlled, it would not have been possible to test the full psychosocial effect of the intervention if subjects were blinded and did not know they were protected. Despite the control group being comparable and selected using the same criteria, it is possible that the intense follow-up with bi-weekly visits to see food allergy specialists during OIT escalation phase positively affected the treatment group caregiver quality of life. However, previous studies looking at allergist interventions such as DBPCFC (positive outcome) and self-regulation telephone intervention did not show significant impact on overall HRQL scores $[22,28]$.

In conclusion, our findings suggest that mOIT, with or without omalizumab, can lead to significant improvements in caregiver HRQL that persist with ongoing treatment. These findings support OIT as a promising therapy for food allergy and suggest that OIT can help relieve the psychosocial burden food allergy imposes on caregivers of food-allergic children. Validated measures of quality of life should be included in future phase II clinical trials.

\section{Additional file}

Additional file 1: Table S1. Food Allergy Quality of Life-Parental Burden Questionnaire.

\section{Abbreviations}

FA: Food allergy; OIT: Oral immunotherapy; mOIT: Oral immunotherapy with multiple food allergens simultaneously; HRQL: Health-related quality of life; FAQL-PB: Food allergy quality of life - parental burden.

\section{Competing interests}

This project was approved by the IRB committee at Stanford University. The authors have no relevant conflict of interest to disclose.

\section{Authors' contributions}

KN conceived and designed the study. IO, CK, TD, AM, LB, and SW acquired data. $I O$ analyzed the data. $I O$ and PB interpreted the data. IO, PB, and KN drafted the manuscript. All authors revised the manuscript and approved the final version.

\section{Acknowledgments}

The authors would like to thank Sharon Chinthrajah, MD, and Jennifer LeBovidge, PhD, for critical reading of the manuscript.

\section{Funding}

Funding for this study was provided by philanthropy and by the Food Allergy Research and Education.

Received: 14 February 2014 Accepted: 15 April 2014

Published: 12 May 2014

\section{References}

1. Gupta RS, Springston EE, Warrier MR, Smith B, Kumar R, Pongracic J, Holl JL: The prevalence, severity, and distribution of childhood food allergy in the United States. Pediatrics 2011, 128(1):e9-e17.

2. Soller L, Ben-Shoshan M, Harrington DW, Fragapane J, Joseph L, St Pierre $Y$, Godefroy SB, La Vieille S, Elliott SJ, Clarke AE: Overall prevalence of self-reported food allergy in Canada. J Allergy Clin Immunol 2012, 130(4):986-988.

3. Boyce JA, Assa'ad A, Burks AW, Jones SM, Sampson HA, Wood RA, Plaut M, Cooper SF, Fenton MJ, Arshad SH, Bahna SL, Beck LA, Byrd-Bredbenner C, Camargo CA Jr, Eichenfield L, Furuta GT, Hanifin JM, Jones C, Kraft M, Levy BD, Lieberman P, Luccioli S, McCall KM, Schneider LC, Simon RA, Simons FE, Teach SJ, Yawn BP, Schwaninger JM: NIAID-Sponsored Expert Panel: Guidelines for the diagnosis and management of food allergy in the United States: report of the NIAID-sponsored expert panel. J Allergy Clin Immunol 2010, 126(6s):S1-S58.

4. Lieberman JA, Sicherer SH: Quality of life in food allergy. Curr Opin Allergy Clin Immunol 2011, 11(3):236-242

5. Sicherer SH, Noone SA, Munoz-Furlong A: The impact of childhood food allergy on quality of life. Ann Allergy Asthma Immuno/ 2001, 87(6):461-464.

6. Avery NJ, King RM, Knight S, Hourihane JO: Assessment of quality of life in children with peanut allergy. Pediatr Allergy Immunol 2003, 14(5):378-382.

7. Gupta R, Holdford D, Bilaver L, Dyer A, Holl JL, Meltzer D: The economic impact of childhood food allergy in the United States. JAMA Pediatrics 2013, 167(11):1026-1031.

8. Cohen BL, Noone S, Munoz-Furlong A, Sicherer SH: Development of a questionnaire to measure quality of life in families with a child with food allergy. J Allergy Clin Immunol 2004, 114(5):1159-1163.

9. Christie L, Hine RJ, Parker JG, Burks W: Food allergies in children affect nutrient intake and growth. J Am Diet Assoc 2002, 102(11):1648-1651.

10. Savage JH, Matsui EC, Skripak JM, Wood RA: The natural history of egg allergy. J Allergy Clin Immunol 2007, 120(6):1413-1417.

11. Nadeau KC, Kohli A, lyengar S, DeKruyff RH, Umetsu DT: Oral immunotherapy and anti-IgE antibody-adjunctive treatment for food allergy. Immunol Allergy Clin North Am 2012, 32(1):111-133.

12. Begin $P$, Winterroth LC, Dominguez T, Wilson SP, Bacal L, Mehrotra A, Kausch B, Trela A, Hoyte E, O'Riordan G, Seki S, Blakemore A, Woch M, Hamilton RG, Nadeau KC: Safety and feasibility of oral immunotherapy to multiple allergens for food allergy. Allergy Asthma Clin Immunol 2014, 10(1):1.

13. Begin P, Dominguez T, Wilson SP, Bacal L, Mehrotra A, Kausch B, Trela A, Travassoli M, Hoyte E, O'Riordan G, Blakemore A, Seki S, Hamilton RG, Nadeau KC: Phase 1 results of safety and tolerability in a rush oral immunotherapy protocol to multiple foods using Omalizumab. Allergy Asthma Clin Immunol 2014, 10(1):2.

14. Flokstra-de Blok BM, van der Velde JL, Vlieg-Boerstra BJ, Oude Elberink JN, DunnGalvin A, Hourihane JO, Duiverman EJ, Dubois AE: Health-related quality of life of food allergic patients measured with generic and disease-specific questionnaires. Allergy 2010, 65(8):1031-1038.

15. Flokstra-de Blok BM, Dubois AE: Quality of life measures for food allergy. Clin Exp Allergy 2012, 42(7):1014-1020. 
16. LeBovidge JS, Haskell H, Borras I, Hoyte E, Umetsu DT, Nadeau KC, Schneider LC: Patient and parent perspectives on quality of life during participation in a study of rapid oral desensitization with omalizumab therapy in patients with milk allergy. J Allergy Clin Immunol 2012, 129(2):AB30.

17. Factor JM, Mendelson L, Lee J, Nouman G, Lester MR: Effect of oral immunotherapy to peanut on food-specific quality of life. Ann Allergy Asthma Immunol 2012, 109(5):348-352. e342.

18. Carraro S, Frigo AC, Perin M, Stefani S, Cardarelli C, Bozzetto S, Baraldi E, Zanconato S: Impact of oral immunotherapy on quality of life in children with cow milk allergy: a pilot study. Int I Immunopathol Pharmacol 2012, 25(3):793-798

19. DunnGalvin A, Cullinane C, Daly DA, Flokstra-de Blok BM, Dubois AE, Hourihane JO: Longitudinal validity and responsiveness of the food allergy quality of life questionnaire - parent form in children $0-12$ years following positive and negative food challenges. Clin Exp Allergy 2010, 40(3):476-485.

20. Kocks JW, Tuinenga MG, Uil SM, van den Berg JW, Stahl E, van der Molen T: Health status measurement in COPD: the minimal clinically important difference of the clinical COPD questionnaire. Respir Res 2006, 7:62

21. Juniper EF, Guyatt GH, Willan A, Griffith LE: Determining a minimal important change in a disease-specific quality of life questionnaire. J Clin Epidemiol 1994, 47(1):81-87.

22. Deyo RA, Diehr P, Patrick DL: Reproducibility and responsiveness of health status measures: statistics and strategies for evaluation. Control Clin Trials 1991, 12(4s):142S-158S

23. Jaeschke R, Singer J, Guyatt GH: Measurement of health status: ascertaining the minimal clinically important difference. Control Clin Trials 1989, 10(4):407-415.

24. van der Velde JL, Flokstra-de Blok BM, de Groot H, Oude-Elberink JN, Kerkhof M, Duiverman EJ, Dubois AE: Food allergy-related quality of life after double-blind, placebo-controlled food challenges in adults, adolescents, and children. J Allergy Clin Immunol 2012, 130(5):1136-1143. e1132.

25. Guyatt GH, Juniper EF, Walter SD, Griffith LE, Goldstein RS: Interpreting treatment effects in randomised trials. BMJ 1998, 316(7132):690-693.

26. Burks AW, Jones SM, Wood RA, Fleischer DM, Sicherer SH, Lindblad RW, Stablein D, Henning AK, Vickery BP, Liu AH, Scurlock AM, Shreffler WG, Plaut M, Sampson HA, Consortium of Food Allergy Research (CoFAR): Oral immunotherapy for treatment of egg allergy in children. $N$ Engl I Med 2012, 367(3):233-243

27. Wasserman RL, Factor JM, Baker JW, Mansfield LE, Katz Y, Hague AR, Paul MM, Sugerman RW, Lee JO, Lester MR, Mendelson LM, Nacshon L, Levy MB, Goldberg MR, Elizur A: Oral immunotherapy for peanut allergy: multipractice experience with epinephrine-treated reactions. J Allergy Clin Immunol Pract 2014, 2(1):91-96.

28. Baptist AP, Dever SI, Greenhawt MJ, Polmear-Swendris N, McMorris MS, Clark NM: A self-regulation intervention can improve quality of life for families with food allergy. J Allergy Clin Immunol 2012, 130(1):263-265. e266.

doi:10.1186/1710-1492-10-25

Cite this article as: Otani et al: Multiple-allergen oral immunotherapy improves quality of life in caregivers of food-allergic pediatric subjects. Allergy, Asthma \& Clinical Immunology 2014 10:25.

\section{Submit your next manuscript to BioMed Central and take full advantage of:}

- Convenient online submission

- Thorough peer review

- No space constraints or color figure charges

- Immediate publication on acceptance

- Inclusion in PubMed, CAS, Scopus and Google Scholar

- Research which is freely available for redistribution

Submit your manuscript at www.biomedcentral.com/submit
C Biomed Central 